\title{
Surrounding Rock Failure Characteristics and Key Control Technology of Double- sided Mining Roadway
}

\author{
Lv Kun ${ }^{1,2,3^{*}}$, Chen Yidong ${ }^{4}$, Feng Jicheng ${ }^{5}$, Wang Jinguo ${ }^{4}$, Guo Qing ${ }^{4}$, Wei Penghui ${ }^{6,7, *}$ and Shen \\ Jinchao $^{6}$
}

\author{
IMine Safety Technology Branch of China Coal Research Institute, Beijing 100013, China \\ ${ }^{2}$ State Key Laboratory of Coal Mining and Clean Utilization (China Coal Research Institute), Beijing 100013, China \\ ${ }^{3}$ College of Safety Science and Engineering, Liaoning Technical University, Fuxin, Liaoning 123000, China \\ ${ }^{4}$ Yan'an Hecaogou Coal Industry Co Ltd., Yan'an 717300, China \\ ${ }^{5}$ School of Safety Engineering, North China Institute of Science and Technology, Yanjiao, 101601, China \\ ${ }^{6}$ School of Energy and Mining Engineering, China University of Mining and Tehnology, Beijing, 100083, China \\ ${ }^{7}$ Department Mineral Resources Engineering, Montanuniversität Leoben University, Leoben, A-8700 LEOBEN, Austria
}

Received 3 January 2020; Accepted 19 March 2020

\begin{abstract}
Mining disturbance is an important influencing factor for the failure of roadway surrounding rock. In general, a main roadway is less affected by the advance mining of a working face. The failure of a main roadway surrounding rock becomes severe when it is affected by double-sided mining. This study explores and analyzes the structural characteristics of a west area main roadway surrounding rock to improve the stability of the main roadway surrounding rock in an area affected by severe stress from double-sided mining. Subsequently, the stress field superposition effect and failure law of a main roadway surrounding rock when the working faces on both sides face the same mining are proposed through numerical analysis with FLAC3D. On this basis, the space trinity control technology of "Key strata + Key part + Key area" is suggested, and the control effect of the main roadway surrounding rock is tested at the end. Results show that the approximate 0-3 m range of the main roadway roof is the key strata controlled by the main roadway roof. When the main roadway is affected by driving, single-sided mining, and double-sided mining, the surrounding rock stress increases gradually, and the horizontal stress increase is much larger than the vertical stress increase. Maximum horizontal stress and maximum vertical stress concentration factors are 3.8 and 2.6, respectively. When transitioning from single-sided to double-sided mining, the plastic zone at two corners of the roof and floor of the main roadway expands gradually to the middle until the shallow portion is completely destroyed. With the interleaving of the two working faces, the expanded plastic zone of the roof extends axially to the range of approximately $\pm 150 \mathrm{~m}$ from the main roadway, and the floor is within the range of $\pm 50 \mathrm{~m}$. The plastic zones of the two sides are small. The test roadway remains stable until the mining of both working faces is complete. This study can provide a theoretical reference for the stability control of main roadway surrounding rock under the influence of mining.
\end{abstract}

Keywords: Double-sided mining, Main roadway, Plastic zone of the surrounding rock, Key control technology

\section{Introduction}

The geological environment of a coal mine roadway is complex, and rock mass properties may change within several hundred or dozens of meters. Therefore, the mechanical properties of surrounding rocks show substantial differences in different locations [1]. When affected by mining, the law of stress distribution around a roadway and the law of surrounding rock failure become extremely complicated owing to the rocks' mechanical properties. Thus, targeted support is important to maintain roadway stability.

Failure of surrounding rock can be divided into three types. The first type involves deep mining and deep underground engineering. The self-gravity stress field of a rock mass is very large owing to the deep burial depth of the engineering. Second, underground mining activities can lead to the superposition effect of the stress field. Third, the strength of a rock mass is very low, and evident deformation

*E-mail address: lukun2004@126.com

ISSN: $1791-2377$ @ 2020 School of Science, IHU. All rights reserved.

doi:10.25103/iestr.132.21 and failure can occur under low stress level conditions. This type involves the large deformation of expansive soft rock. The three types of surrounding rock failure mechanism and the support technology of underground engineering differ. Given that the first and third types of surrounding rock failure mechanism are apparent, local and international scholars [2-7] have conducted considerable research on these types of failures, and mature support theories and methods have been formed. The second type of roadway failure is caused by the complex stress field generated by mining. In the past, support for this type of roadway generally applied the first and third types of support theories and methods. This practice has led to the unclear understanding of the surrounding rock failure mechanism of this type of roadway and has not been taken seriously. Roadway support in numerous mines has remained in a passive state.

Failure of roadway surrounding rock is essentially caused by the formation and development of the surrounding rock plastic zone. The geometry and scope of the plastic zone determine the mode and degree of the surrounding rock failure. Research on the failure mechanism of roadway 
surrounding rock focuses on the formation and development laws of the surrounding rock plastic zone. Moreover, the distribution characteristics of a surrounding rock plastic zone are important theoretical bases for determining support parameters for roadways. For example, the anchoring depth of a bolt must be deeper than the depth of a failure zone, and roof stress is influenced by the plastic failure zone. The distribution characteristics of a roadway plastic zone can provide scientific evidence for the design of roadway support parameters.

This study analyzes the superposition effect and failure law of the stress field of a main roadway surrounding rock when the working faces of the main roadway's double sides face the same mining. A reasonable and effective control scheme is proposed, and reference for the control of similar main roadways is provided.

\section{State of the art}

The deformation and failure of roadway surrounding rock are the result of the formation and development of a surrounding rock plastic zone. The mechanism of the surrounding rock deformation and failure can be revealed only on the basis of the research on the formation mechanism and development law of a surrounding rock plastic zone. Local and international scholars have used theoretical derivation and numerical simulation to examine roadway surrounding rock failure and control technology. Theoretical derivation is deduced and analyzed based on elastoplastic and viscoelastic mechanics and combined with a series of failure criteria, such as the Mohr-Coulomb criterion, the Drucker-Prager criterion, and unified strength theory in material mechanics. For example, Kastner and Fenner [8] based their work on the Mohr Coulomb failure criterion. The Kastner equation for the stress and radius of the elastoplastic zone of a round chamber surrounding rock was obtained based on an ideal elastoplastic model and invariant volume after rock failure hypothesis. Zareifard et al. [9] proposed a full analytical solution considering the seepage force generated by steady-state flow based on elastic brittle plasticity and Mohr-Coulomb rock material analysis. The simplified analytical solution can be used to approximate a circular design of holes, such as a tunnel excavated under the groundwater level. Sharan [10] developed a closed-form solution based on the Hoek-Brown medium to predict the displacement of circular holes in brittle rock masses under the action of the hydrostatic stress field and verified the closed-from solution using the finite element method. Park et al. [11] discussed the analytical solution of the circular hole displacement prediction of elastic-brittle-plastic rock masses applicable to the linear Mohr-Coulomb criterion or the nonlinear Hoek-Brown yield criterion. Based on the nonassociative flow law, the same closed-form analytical solution for plastic zone displacement in all cases was derived theoretically. Zheng et al. [12] used a generalized plane strain problem and unified strength theoretical knowledge to derive the elastoplastic failure equation of roadway surrounding rock under the action of triaxial stress and analyzed the plastic failure zone of the floor of roadway \#1 in the S6 mining area of the Changcun coal mine. In the aforementioned studies, the theoretical model is a homogeneous medium, and several errors exist between the theoretical calculation and actual results.
In terms of numerical simulation, actual engineering background is taken mainly as an example, and simulation analysis is performed by a numerical calculation software. For example, Coggan et al. [13] used numerical simulation to simulate the adverse effect of high-level stress and weak direct roof lithology on the roof stability of a roadway and discussed combing with a concrete example. Basarir et al. [14] employed the mining roadway of the Guobei coal mine as the engineering background, adopted the global-local modeling method to analyze the stability of the mining roadway, and proposed a support system consisting of bolts, anchor cables, and shotcrete. Zhao et al. [15] took the Baode coal mine as the engineering background and analyzed the relationship between the distribution pattern of the roadway plastic zone and mining stress through numerical simulation. Butterfly plastic zone theory and its control concept were proposed and applied to numerous engineering sites. Tai et al. [16] used the mechanical and electrical chamber of the Tashan coal mine as the engineering background and analyzed the deformation and failure characteristics of the surrounding rock of the chamber using numerical simulation. A control method for high-strength bolts and anchor cables combined with grouting reinforcement was proposed, and the engineering verification effect was satisfactory. Jia et al. [17] took the Baode coal mine as an example to analyze the nonuniform characteristic of the plastic failure zone of the roadway roof under the superposition of original rock stress and mining stress. A layered support design scheme based on long bolts was proposed according to the characteristic of the plastic zone of the composite-layer structured roof, and the control was effective. Pan et al. [18] employed the Pingbao coal mine as the engineering background and used the FLAC3D software to simulate the stress distribution, surrounding rock displacement, and plastic zone distribution characteristic of the bed plate roadway under various disturbances. In addition, the authors designed the "boltnet-cable-beam" support method. Xu et al. [19] used the Wantian coal mine in Guizhou as an example, established a numerical model according to stope conditions, and analyzed the change rules in the stress, displacement, and plastic zone around the roadway during the mining of the overlying coal seam. The broken surrounding rock of the floor was reinforced by grouting, the roof and two sides were supported by high prestress anchor cables, and the floor was supported by birdcage anchor cables. The deformation of the roadway was controlled, and the support requirement was satisfied. Zhang et al. [20] took the Gaojiaba coal mine as an example and used numerical simulation to simulate the deformation characteristic of the surrounding rock of the gob-side entry under dynamic load. The deformation characteristic of the gob-side entry and the concept of pressure coupling support were combined, and an optimal design scheme for bolt support was proposed. Field application was implemented, and the loosening, deformation, and failure of the roadway surrounding rock were controlled effectively. Yuan et al. [21] focused on the large deformation and difficult maintenance of the mining roadway in the fully mechanized working face of the Wangzhuang coal mine. FLAC3D was used to numerically simulate the stress evolution and deformation characteristics of the roadway surrounding rock, and the surrounding rock control scheme combining high prestress anchor structure with self-moving advanced hydraulic support was proposed. The effectiveness of the support scheme was verified through onsite application. In the aforementioned numerical simulations, research results are obtained on the failure and 
control of roadway surrounding rock according to different engineering geological conditions. However, minimal research has been conducted on the control of main roadway surrounding rock under the influence of double-sided mining.

Thus, given the shortcomings of existing research, this study takes the Hecaogou coal mine as the engineering background and simulates and analyzes the characteristics of the stress and plastic zone changes of the main roadway surrounding rock under different mining-influenced stages with the FLAC3D software. Key control technology of the space trinity is proposed and verified through engineering application to provide a theoretical basis for the stability control of surrounding rock under the influence of mining.

The remainder of this study is organized as follows. Section 3 expounds the engineering overview, finite difference modeling method, and engineering practice. Section 4 analyzes the roof stratum structure, double-sided mining-superimposed stress field, and the surrounding rock plastic zone; proposes the reasonable technical control scheme of the double-sided mining roadway; and verifies the control effect of the scheme. Section 5 summarizes the conclusions.

\section{Methodology}

\subsection{Engineering overview}

\subsubsection{Engineering geological condition}

The Hecaogou coal mine 5\# coal seam is the main coal seam. The buried depth is approximately $300 \mathrm{~m}$, and the average coal seam thickness is approximately $2.24 \mathrm{~m}$. According to the drilling data of H404, H405, and H406 near the west area main roadway, the rock stratum lithology within a range of $0-12 \mathrm{~m}$ at the roof is all gray-black oil shale, and the thin layers of gray-white bauxite mudstone are interlaced. The length of the west area main roadway is $2470 \mathrm{~m}$, and the width of the coal pillar between the No. 50114 working face and the west area auxiliary transportation main roadway is $93 \mathrm{~m}$. The width of the coal pillar between the No. 50201 working face and the west area belt conveying main roadway is $100 \mathrm{~m}$. The space distance of the main roadways is $35 \mathrm{~m}$. When the west area main roadway was affected by single-sided mining in the early stage, the roof corner showed a step sinking, the concrete slagged partly, and risk of roof collapse was high (Fig. 1).
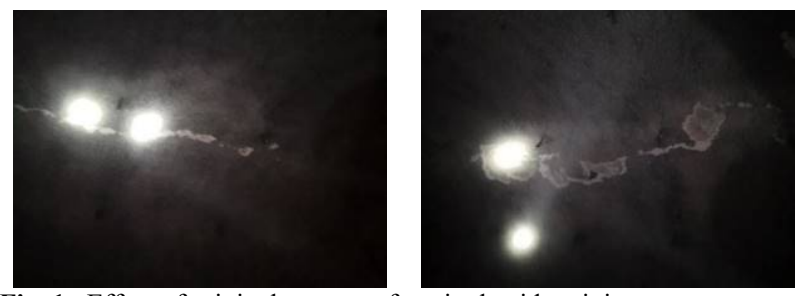

Fig. 1. Effect of original support after single-side mining

With two working faces advancing in opposite directions simultaneously, mining can be exploited to the same position of approximately $1150 \mathrm{~m}$ from the west area main roadway, as shown in Fig. 2. The dynamic superposition of doublesided mining stress is inevitable before and after the advance to the same position. This situation would increase the failure of the roadway roof surrounding rock and may cause a large area of concrete slagging, which may cause injuries and block vehicles and pedestrians in the main roadway. A dire situation would involve the breaking of the bolts and anchor cables, thereby leading to a roof collapse accident.

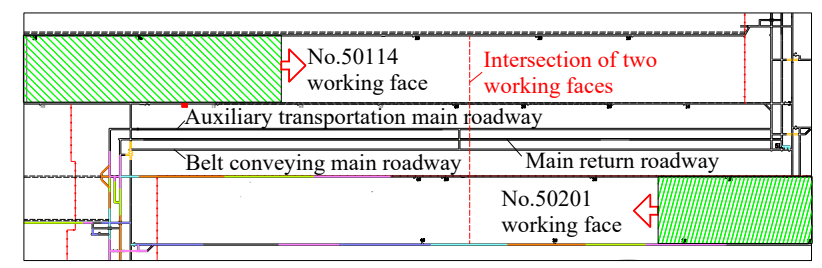

Fig. 2. Schematic diagram of double-sided mining on west area main roadway

\subsubsection{Surrounding Rock Exploration Scheme}

The onsite production and geological conditions of the Hecaogou coal mine must be considered according to the research needs. Coring and borehole peering should be used to obtain a combination of the main roadway roof strata and the thickness and distribution law of the bauxite mudstone in the oil shale.

(1) The ZLJ-650 underground geological drilling rig of the Hecaogou mine is used to obtain a group of roof cores at the link-roadway between 1200 and $2400 \mathrm{~m}$ of the west area auxiliary transportation roadway and the west area main return roadway. The oblique angle between the coring angle and the roof and floor is 45 . A $\varphi 93$ coring bit, a $\varphi 89$ coring tube with a length of $1 \mathrm{~m}$, and other drilling tools are used to obtain the rock samples. The coring locations are shown in Fig. 3.

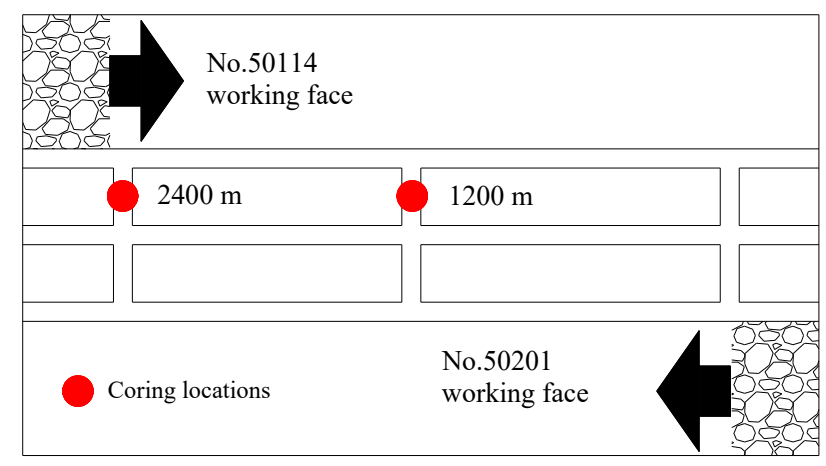

Fig. 3. Schematic diagram of drilling and coring location

(2) The ZKXG30 mine drilling imaging trajectory detection device is used to perform the borehole peering test on the roof of the west area main return roadway, the auxiliary transportation main roadway, the belt conveying main roadway, and the two sides of the main return roadway. Seven holes on the roof and two holes on the two sides are made. The diameter of the holes is $30 \mathrm{~mm}$. The specific borehole peering positions are shown in Fig. 4.

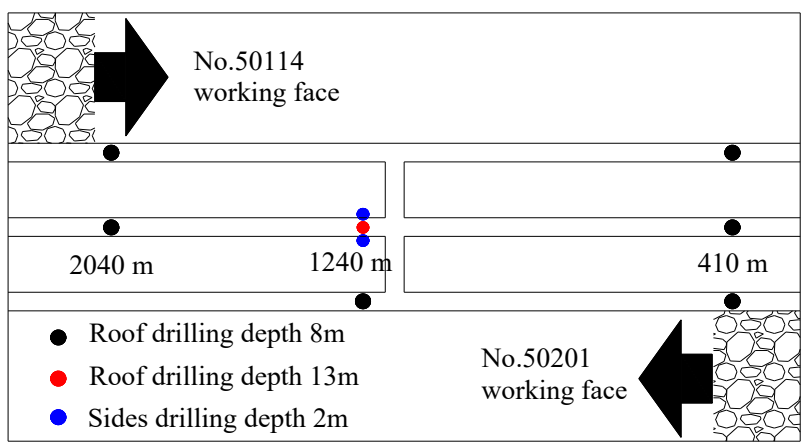

Fig. 4. Schematic diagram of drilling peep point location 


\subsection{Finite difference analysis}

This study employs FLAC3D to perform the modeling analysis on the double-sided mining main roadway surrounding rock stress and plastic zone distribution characteristic. A numerical model is built according to the actual size of the site. This constitutive model adopts the Mohr-Coulomb model.

\subsubsection{Modeling size and boundary conditions}

The length of working faces No. 50114 and No. 50201 is $260 \mathrm{~m}$. The model size is $\mathrm{X} * \mathrm{Y} * \mathrm{Z}=919 * 3700 * 160 \mathrm{~m}$.
The section shape of the three main roadways is a straightwall semicircular arch. The width is $5.7 \mathrm{~m}$, the arch height is $4.8 \mathrm{~m}$, and the straight-wall height is $1.9 \mathrm{~m}$ (Fig. 5).

Vertical stress that is equal to the weight of the overlying stratum is applied to the upper boundary of the model and is 6.91 MPa. The side pressure coefficient is 1.0. Displacement and initial velocity in the $\mathrm{x}$ direction are limited in the horizontal direction of the model. Displacement and initial velocity in the $\mathrm{x}, \mathrm{y}$, and $\mathrm{z}$ directions are limited at the bottom of the model. Each rock stratum mechanical parameter of the model is obtained from the "Hecaogou Coal Mine Geological Report," as shown in Table 1.

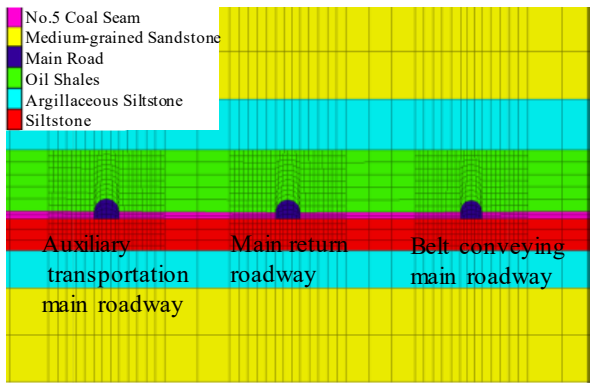

(a)

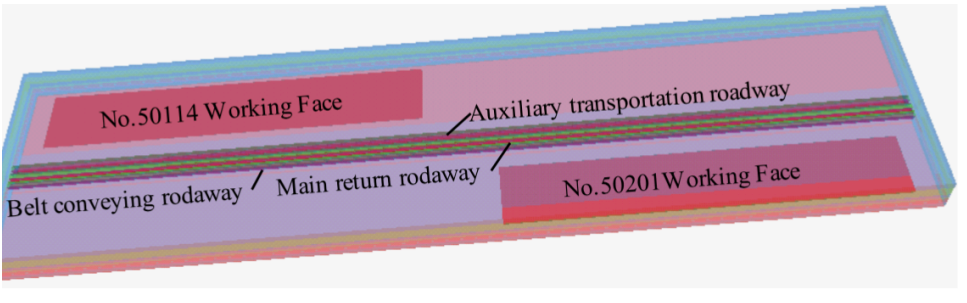

(b)

Fig. 5. Schematic diagram of numerical model

Table 1. Rock mechanical parameters

\begin{tabular}{c|c|c|c|c}
\hline Rock strata & $\begin{array}{c}\text { Bulk } \\
\text { modulus/GPa }\end{array}$ & $\begin{array}{c}\text { Tensile } \\
\text { strength/MPa }\end{array}$ & $\begin{array}{c}\text { Internal friction } \\
\text { angle/ }\end{array}$ & Density/kg/m \\
\hline Cohesion/MPa
\end{tabular}

\subsubsection{Modeling scheme}

In the model, original stress balance is carried out first, then three main roads are excavated. Working faces No. 50114 and No. 50201 are excavated after the model is balanced. Five observing stations, that is, a, b, c, d, and e, are established. Observing station $\mathrm{e}$ is located at the interchange of the two working faces at approximately $1150 \mathrm{~m}$. Observing stations $\mathrm{a}, \mathrm{b}, \mathrm{c}$, and $\mathrm{d}$ are at a distance of approximately $300,200,100$, and $50 \mathrm{~m}$ away from observing station e. A distance of $600 \mathrm{~m}$ from the two working faces is set as the initial position. Distances of 100 , $200,250,300,350,400,500$, and $600 \mathrm{~m}$ continue to advance. Roadway surrounding rock stress distribution and plastic zone distribution at each position are recorded. The monitoring layout is shown in Fig. 6.

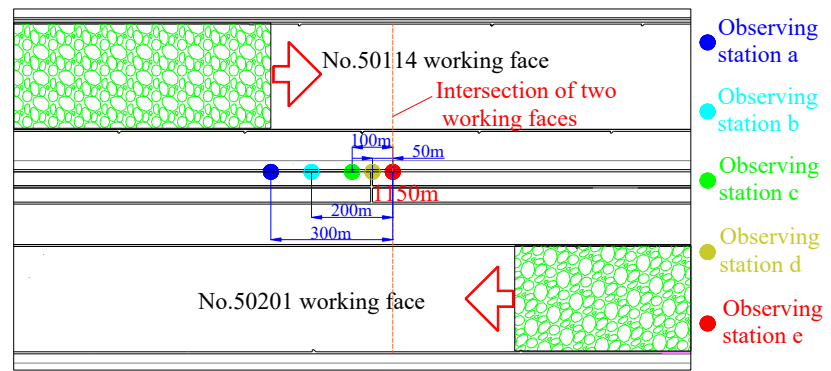

Fig. 6. Model monitoring scheme

\subsection{Engineering validation}

Before the intersection of working faces No. 50201 and No. 50114 , the specific parameters of the pre-implementation support scheme are as follows.

Original support scheme: The bolt is a sinistral and ribless steel bolt with a diameter of $20 \mathrm{~mm}$, a length of 2400 $\mathrm{mm}$, and a row space of $900 \mathrm{~mm} \times 900 \mathrm{~mm}$. The support plate is a $150 \mathrm{~mm} \times 150 \mathrm{~mm} \times 12 \mathrm{~mm}$ metal steel plate. The resin medicine-one is a MSCK28/35 type, and three rolls are used for each bolt. The diameter of the mesh is $\Phi 6.5 \mathrm{~mm}$, the grid is $100 \mathrm{~mm} \times 100 \mathrm{~mm}$, the specification is $2400 \mathrm{~mm}$ $\times 1000 \mathrm{~mm}$, the overlapping length of steel meshes is 100 $\mathrm{mm}, 14 \#$ double-stranded iron wires are used for symmetric binding, and the binding distance should not be larger than $300 \mathrm{~mm}$. The anchor cable is $\Phi 17.8 \mathrm{~mm} \times 7900 \mathrm{~mm}$, and the support plate is $300 \mathrm{~mm} \times 300 \mathrm{~mm} \times 16 \mathrm{~mm}$. Five MSCK28/35 type resin medicine-ones are used for each anchor cable, and the prestress of the anchor cable should not be less than $140 \mathrm{kN}$. A ladder beam of $\varphi 18$ round steel $(4000 \mathrm{~mm} \times 150 \mathrm{~mm})$ is used. The row space between the anchor cables is $1800 \mathrm{~mm} \times 1800 \mathrm{~mm}$.

Reinforcing support scheme: Three anchor cables that are $\Phi 17.8 \mathrm{~mm} \times 7900 \mathrm{~mm}$ are used on the main roadway roof, two of which are installed at the shoulder of the roof (the angle of the vertical direction is 45 degrees), and one is installed at the top of the positive arc. The row space between the anchor cables is $1800 \mathrm{~mm} \times 1800 \mathrm{~mm}$. The support plate is $300 \mathrm{~mm} \times 300 \mathrm{~mm} \times 16 \mathrm{~mm}$. Five MSCK28/35 type resin medicine-ones are used for each 
anchor cable. A ladder beam of $\varphi 18$ round steel $(4000 \mathrm{~mm} \times$ $150 \mathrm{~mm}$ ) is used. The diameter of the mesh is $\varphi 6.5 \mathrm{~mm}$, the grid is $100 \mathrm{~mm} \times 100 \mathrm{~mm}$, the specification is $2400 \mathrm{~mm} \times$ $1000 \mathrm{~mm}$, the overlapping length of steel meshes is $100 \mathrm{~mm}$, 14\# double-stranded iron wires are used for symmetric binding, and the binding space should not be larger than 300 $\mathrm{mm}$. The support area is located approximately $150 \mathrm{~m}$ from the front and back of the intersection of the two working faces (Fig. 7).
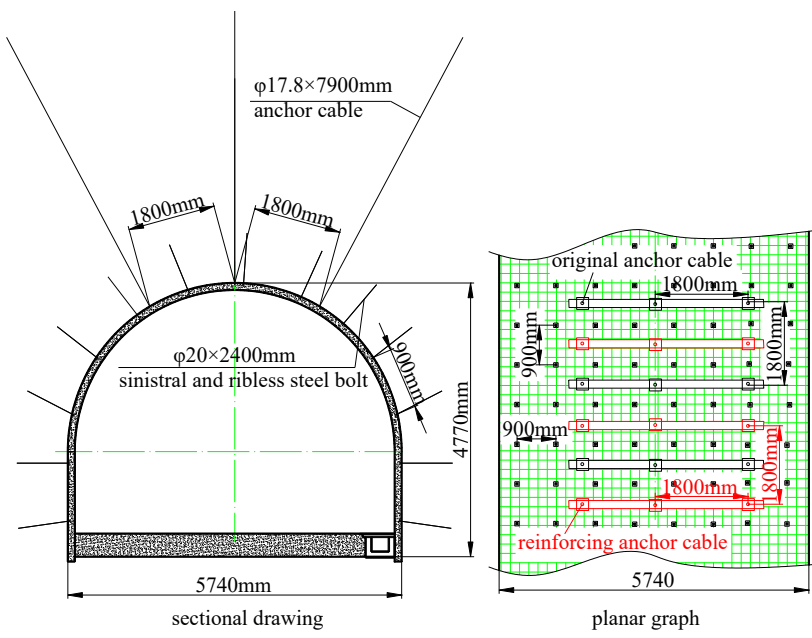

Fig. 7. The west area main roadway support scheme

The test roadway support area is within the range of $850-1450 \mathrm{~m}$ in the west area main return roadway. Surface displacement observation points are set at a location approximately 1100 and $1200 \mathrm{~m}$ in the west area main return roadway. After the main roadway is affected by mining, the displacement of the roof, floor, and two sides of the roadway is monitored to verify the control effect of the proposed support scheme on the surrounding rock.

\section{Result analysis and discussion}

\subsection{Analysis of roof rock stratum structure}

The link-roadway roof core characteristic at a position approximately $1200 \mathrm{~m}$ from the west area auxiliary transportation main roadway and the west area main return roadway is shown in Table 2 . Within the range of $0-1 \mathrm{~m}$ from the drilling hole (vertical height is $0-0.7 \mathrm{~m}$ ), the rock is mainly light gray and composed of bauxite mudstone with poor integrity. Within the range of $1.0-5.0 \mathrm{~m}$ from the drilling hole (vertical height is $0.7-3.4 \mathrm{~m}$ ), the rock is mainly gray-black, mainly composed of oil shale, and mixed with a small thin bauxite mudstone layer. This section of the rock core demonstrates a high degree of change and poor integrity. Within the range of 5.0-10.5 m (vertical height is 3.4-7.4 m), the rock is gray and mainly composed of argillaceous siltstone mixed with a small amount of gray-black oil shale. This section of the rock core exhibits a low degree of change and good integrity. Within the range of 10.5-13.5 m (vertical height is 7.4-9.6 m) from the drilling hole, the rock is mainly gray-black and composed of oil shale mixed with a small amount of bauxite mudstone. This section of the rock core has a low degree of change and good integrity.

Table 2. Roof core characteristics at $1200 \mathrm{~m}$

\begin{tabular}{c|c|c}
\hline Core photos & $\begin{array}{c}\text { Oblique } \\
\text { depth/m }\end{array}$ & $\begin{array}{c}\text { Vertical } \\
\text { height } / \mathbf{m}\end{array}$ \\
\hline n & $0-1$ & $0-0.7$
\end{tabular}

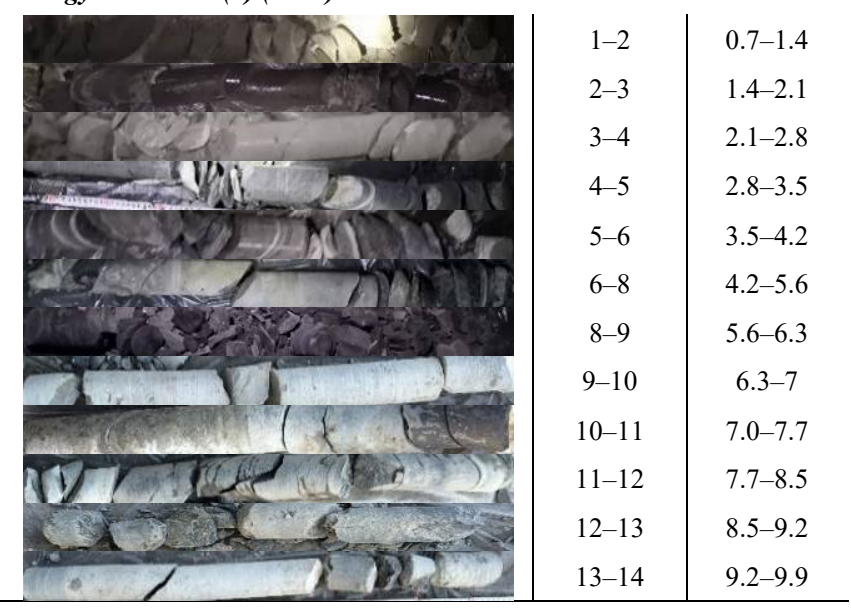

The link-roadway roof core characteristic at a position approximately $2400 \mathrm{~m}$ from the west area auxiliary transportation main roadway and the west area main return roadway is shown in Table 3 . Within the range of $0-1 \mathrm{~m}$ from the drilling hole (vertical height is $0-0.7 \mathrm{~m}$ ), the rock is mainly gray and white and composed of bauxite mudstone with poor integrity. Within the range of $1.0-5.0 \mathrm{~m}$ (vertical height is $0.7-3.4 \mathrm{~m}$ ), the rock is mainly gray-black and composed of oil shale mixed with a small amount of thin light gray bauxite mudstone layer. This section of the rock core demonstrates a high degree of change and poor integrity. Within the range of 5.0-10.5 $\mathrm{m}$ (vertical height is 3.4-7.4 m), the rock is mainly gray and composed of argillaceous siltstone mixed with a small amount of gray-black oil shale and light gray bauxite mudstone in the middle. This section of the rock core exhibits low degree of change and good integrity. Within the range of $10.5-13.5 \mathrm{~m}$ from the hole (vertical height is 7.4-9.5 m), the rock is mainly gray-black and composed of oil shale mixed with a small amount of thin bauxite mudstone layer. This section of the rock core has a high degree of change and poor integrity.

Table 3. Roof core characteristics at $2400 \mathrm{~m}$

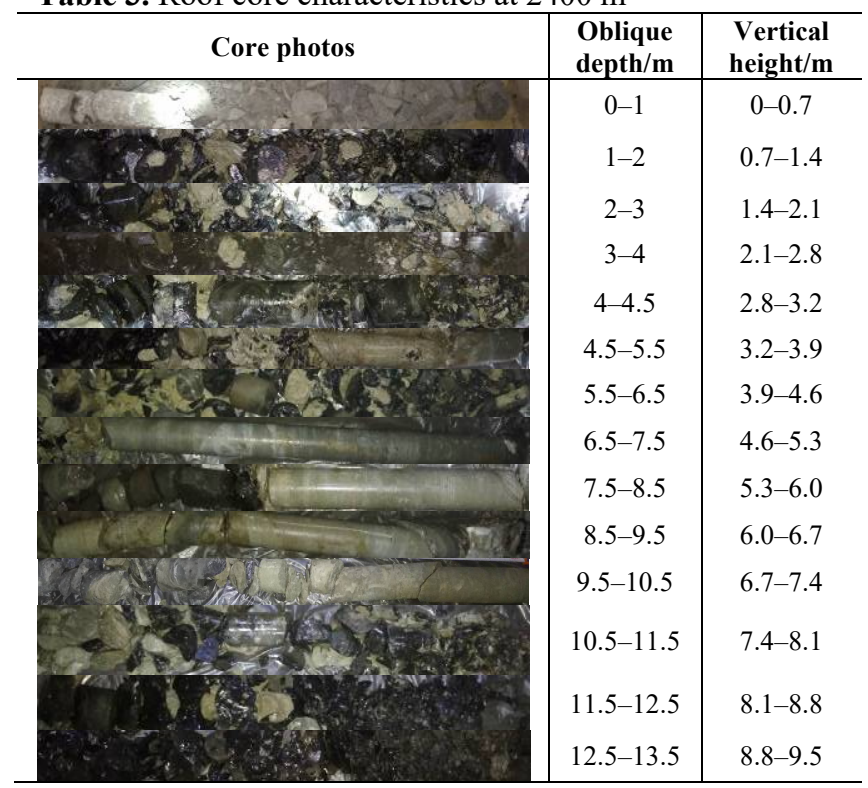

According to the results of the borehole peering, the main roadway roof is mainly oil shale and contains thin bauxite mudstone layers and thin argillaceous siltstone oil shale layers. The main return roadway is taken as an 
example. The results of the roof borehole peering at 410 , 1240, and $2040 \mathrm{~m}$ are shown in Fig. 8. The following findings are determined from the analysis in Fig. 8.

(1) The lithology of the main roadway roof stratum within the range of $0-13 \mathrm{~m}$ is oil shale with the thin bauxite mudstone layers and argillaceous siltstone with the thin oil shale layers. Within the range of 410-2240 m, the thickness of the main roadway roof low oil shale ranges from $3.0 \mathrm{~m}$ to $6.1 \mathrm{~m}$, and the thickness of the argillaceous siltstone adjacent to the oil shale ranges from $3.4 \mathrm{~m}$ to $6.9 \mathrm{~m}$. Within the range of $410-1240 \mathrm{~m}$, the overall thickness of the oil shale increases slightly from $4.6 \mathrm{~m}$ to $6.1 \mathrm{~m}$, and the overall thickness of the argillaceous siltstone increases considerably from $3.4 \mathrm{~m}$ to $6.9 \mathrm{~m}$. Within the range of $1240-2240 \mathrm{~m}$, the overall thickness of the oil shale decreases substantially from $6.1 \mathrm{~m}$ to $3.0 \mathrm{~m}$, and the overall thickness of the argillaceous sandstone decreases markedly from $6.9 \mathrm{~m}$ to $3.85 \mathrm{~m}$.
(2) The enrichment region of the oil shale and bauxite mudstone rock line focuses in the range of 1.2-1.8 $\mathrm{m}$ above the roof. The enrichment region of the extremely thin 1-2 $\mathrm{cm}$ bauxite mudstone stratum is mainly in the range of $0-1.1$ $\mathrm{m}$ above the roof. The enrichment region of the thin 5-10 $\mathrm{cm}$ bauxite mudstone layer focuses in the range of $0-2 \mathrm{~m}$ above the roof, and the height from the roof layer decreases gradually from $410 \mathrm{~m}$ to $1240 \mathrm{~m}$ to $2240 \mathrm{~m}$. The "marbled meat" enrichment region of the bauxite mudstone and oil shale is in the range of $2-3 \mathrm{~m}$ above the roof. Therefore, the $0-3 \mathrm{~m}$ range of the main roadway roof is a weak composite stratum. This layer is vulnerable to plastic failure under the action of mining-superimposed stress owing to multiple layers of weak mudstone. This stratum is unstable and a key layer in roadway support control.

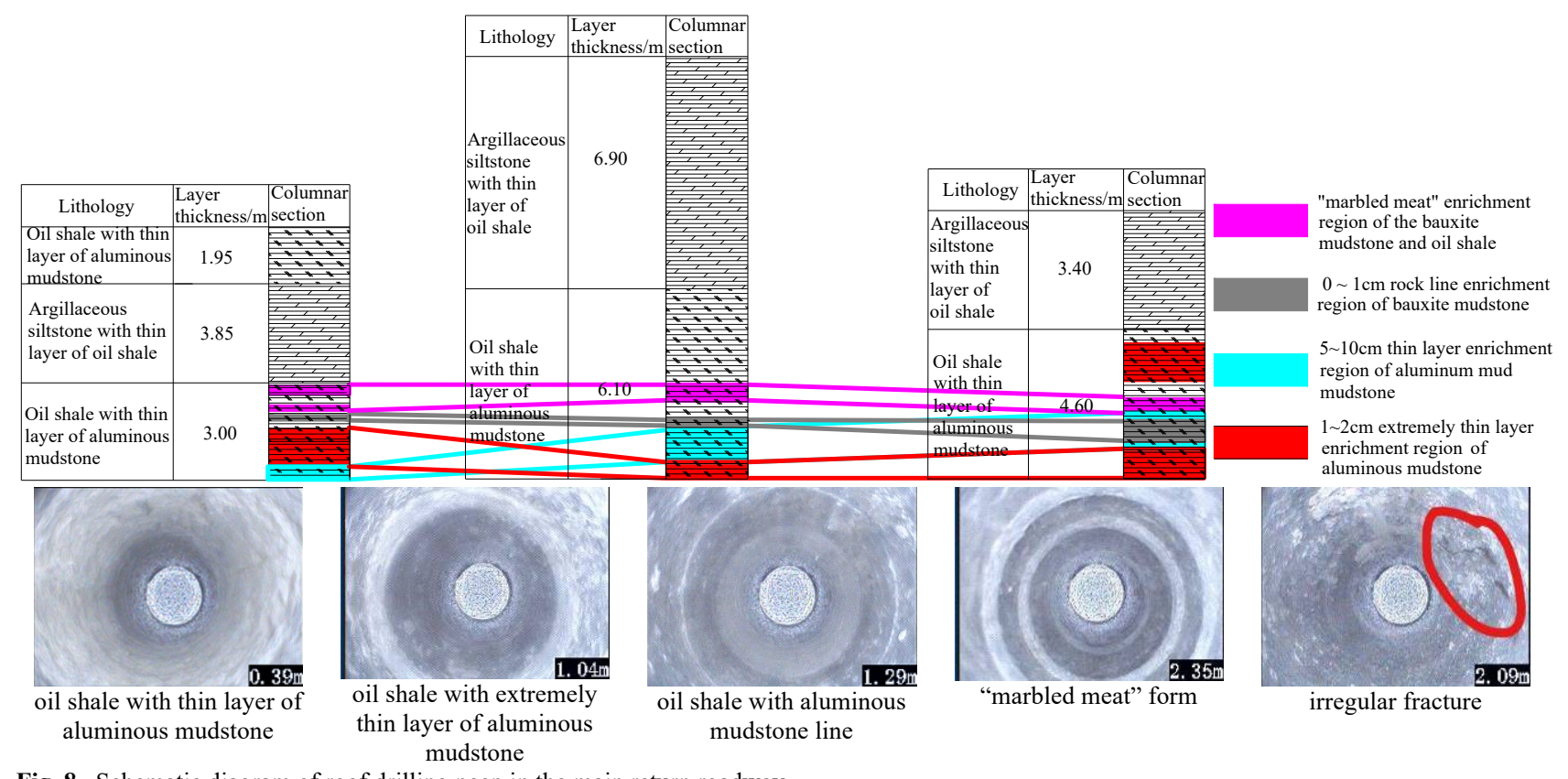

Fig. 8. Schematic diagram of roof drilling peep in the main return roadway

\subsection{Analysis of double-sided mining main roadway surrounding rock stress field-superimposed effect}

The two working faces on both sides of the main roadway advance simultaneously. The vertical and horizontal stress distributions of stations a, c, and e when the working faces advance 0,300 , and $600 \mathrm{~m}$ are shown in Table 4 .

Table 4 shows that when the west area main roadway is not disturbed by the engineering, the vertical stress is 9.7 $\mathrm{MPa}$. In the excavation period, the maximum vertical stress around the roadway is $15 \mathrm{MPa}$, which is 1.5 times the original rock stress. Before the intersection of working faces No. 50114 and No. 50201, the main roadway is affected by single-sided mining, and the maximum vertical stress around the roadway is $20 \mathrm{MPa}$, which is located on the two sides of the roadway. The stress concentration factor is 2.1 , which is 1.3 times the excavation period. After the intersection of working faces No. 50114 and No. 50201, the main roadway is affected by double-sided mining. The vertical stress is superimposed and is $25 \mathrm{MPa}$. The stress concentration factor is 2.6 , which is 1.7 times the excavation period.

When the west area roadway is not disturbed by engineering, the horizontal stress is $7.8 \mathrm{MPa}$. In the excavation period, the maximum horizontal stress is $13 \mathrm{MPa}$, which is 1.7 times the original rock stress. Before the intersection of working faces No. 50114 and No. 50201, the main roadway is affected only by single-sided mining. The maximum horizontal stress around the roadway is $20 \mathrm{MPa}$, which is located on the roof. The stress concentration factor is 2.5 , which is 1.5 times the excavation period. After the intersection of working faces No. 50114 and No. 50201, the main roadway is affected by double-sided mining. A superimposed horizontal stress phenomenon occurs around the roadway and reaches $30 \mathrm{MPa}$. The stress concentration factor is 3.8 , which is 2.3 times the excavation period.

The datum of measurement point e are taken as a sample, and the evolution rule of vertical and horizontal stress is drawn (Fig. 9).

Table 4. Distribution characteristics of vertical and horizontal stresses

Table 4. Distribution characteristics of vertical and horizontal stresses
Vertical stress distributions

\begin{tabular}{l|l|c|c} 
Station & Working faces advance $0 \mathrm{~m}$ & Working faces advance $300 \mathrm{~m}$ & Working faces advance $600 \mathrm{~m}$ \\
\hline
\end{tabular}


Lv Kun, Chen Yidong, Feng Jicheng, Wang Jinguo, Guo Qing, Wei Penghui and Shen Jinchao/ Journal of Engineering Science and Technology Review 13 (2) (2020) 174 - 184

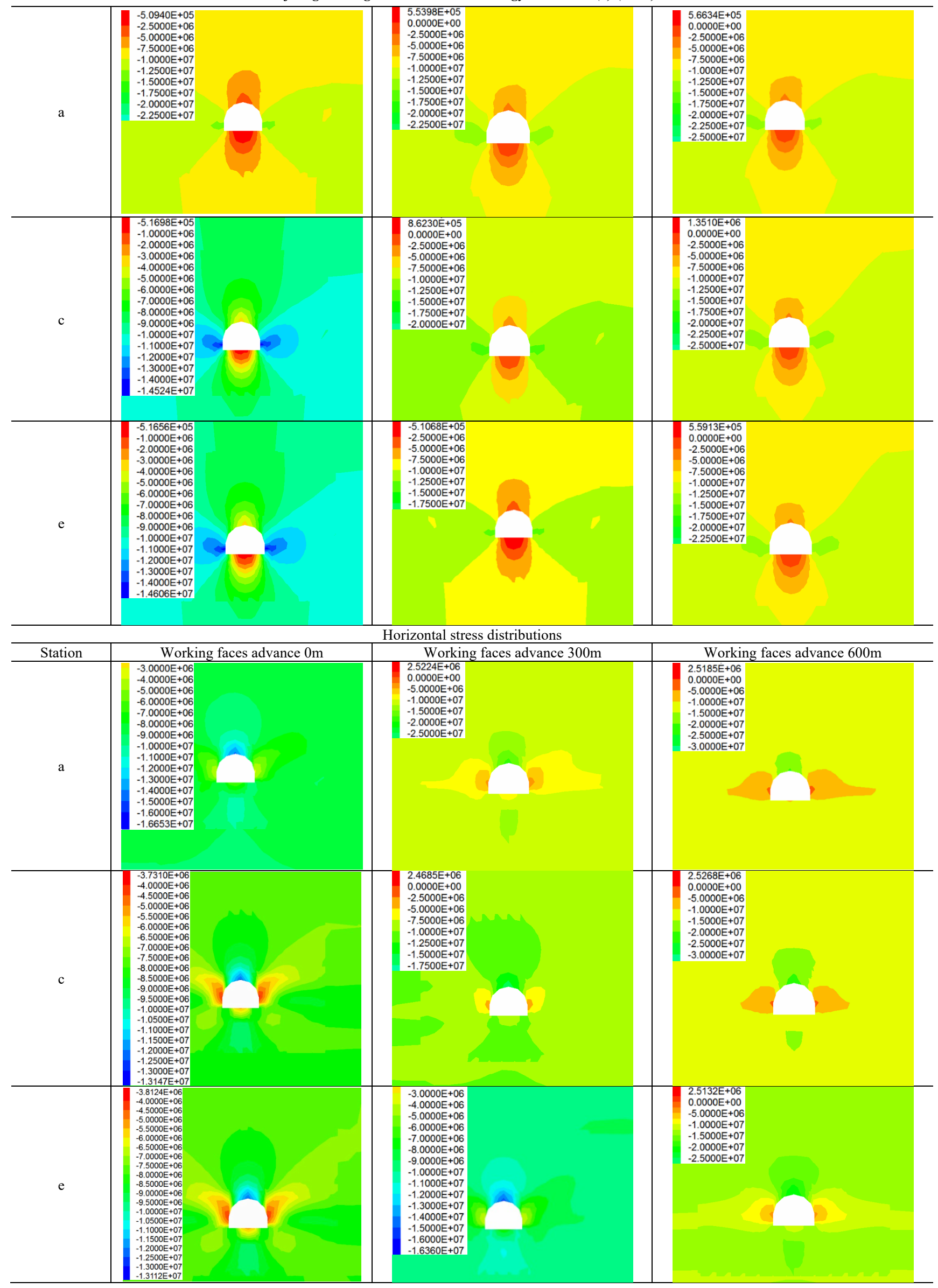




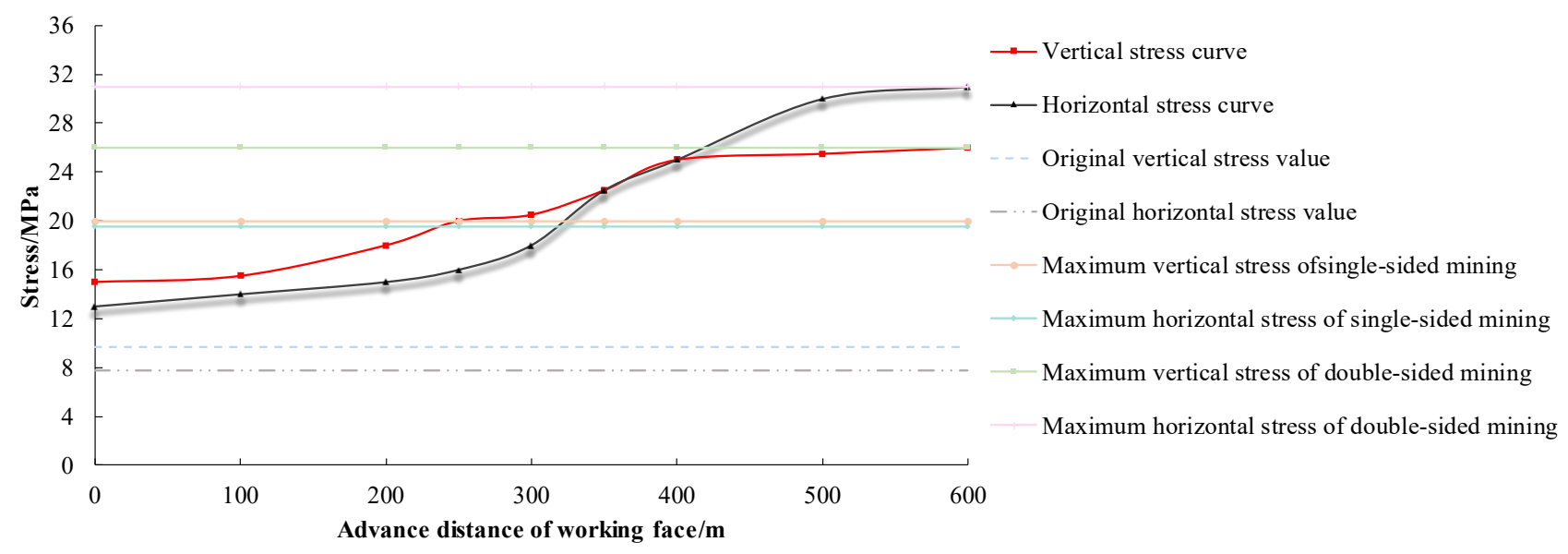

Fig. 9. Evolution law of vertical and horizontal stress

Before the working faces advance to the intersection, the main roadway at station e is affected by engineering disturbances (Fig. 9). The vertical stress at the two sides of the main roadway and the horizontal stress at the roof are larger than the original rock stress. The vertical stress is larger than the horizontal stress. When the working faces advance, station e is affected by single mining, and vertical stress and horizontal stress increase gradually. After the working faces advance $300 \mathrm{~m}$ to the intersection, the main roadway is affected by double-sided mining. Horizontal stress increases sharply. The horizontal stress increase is larger than the vertical stress increase. As the working faces continue to advance, horizontal stress exceeds vertical stress and reaches $30 \mathrm{MPa}$. Vertical stress reaches $25 \mathrm{MPa}$.

In conclusion, during the period when the main roadway is affected by driving, single-sided mining, and double-sided mining, the horizontal stress increase at the roof and floor of the main roadway is substantially larger than the vertical stress increase at the two sides of the main roadway. The horizontal stress concentration factor of the intense miningsuperimposed stress region increases to 3.8 , whereas the vertical stress concentration factor increases to 2.6. The stability of the surrounding rock depends mainly on horizontal stress. After the roadway is affected by doublesided mining, the horizontal stress increase at the roadway roof is severe. Preventing the vicious evolution of the surrounding rock failure area of the roadway roof is extremely important to ensure the stability of the roadway.

\subsection{Analysis of surrounding rock failure rules in double-} sided mining roadways

During the advancement of the working faces, the distribution of the surrounding rock plastic zone of the west area auxiliary transportation main roadway and belt conveying main roadway is calculated, as shown in Table 5.

Table 5. Distribution of plastic zone affected by mining

\begin{tabular}{|c|c|c|c|c|c|}
\hline \multirow{2}{*}{$\begin{array}{c}\text { Advance distance of } \\
\text { working face } / \mathrm{m}\end{array}$} & & \multicolumn{2}{|c|}{ Auxiliary transportation main roadway } & \multicolumn{2}{|c|}{ Belt conveying main roadway } \\
\hline & & advance influence scope $/ \mathbf{m}$ & lag-influence scope/m & $\begin{array}{c}\text { advance influence } \\
\text { scope/m }\end{array}$ & $\begin{array}{c}\text { lag-influence } \\
\text { scope/m }\end{array}$ \\
\hline \multirow[t]{3}{*}{ 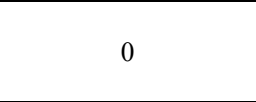 } & Roof & 40 & - & 5 & - \\
\hline & Sides & - & - & - & - \\
\hline & Floor & - & - & - & - \\
\hline \multirow{3}{*}{200} & Roof & 35 & - & - & 25 \\
\hline & Sides & - & 115 & - & - \\
\hline & Floor & - & 60 & - & 90 \\
\hline \multirow{3}{*}{250} & Roof & 30 & - & - & 25 \\
\hline & Sides & - & 120 & - & 235 \\
\hline & Floor & - & 85 & - & 125 \\
\hline \multirow{3}{*}{300} & Roof & 40 & 215 & - & 15 \\
\hline & Sides & - & 125 & - & 240 \\
\hline & Floor & - & 60 & - & 95 \\
\hline \multirow{3}{*}{400} & Roof & 150 & 55 & - & 0 \\
\hline & Sides & - & 90 & - & 170 \\
\hline & Floor & 75 & 50 & 70 & 80 \\
\hline \multirow{3}{*}{600} & Roof & - & 170 & - & 5 \\
\hline & Sides & - & 120 & - & 230 \\
\hline & Floor & - & 20 & - & 30 \\
\hline
\end{tabular}

Table 5 shows that before the intersection of the working faces, the three main roadways are affected only by singlesided mining. The advance influence range of the auxiliary transportation main roadway roof is $40 \mathrm{~m}$ in front of the No. 50114 working face. The influence that the No. 50201 working face exerts on the belt conveying main roadway is a lagged influence. The range of the lagged influence is $25 \mathrm{~m}$ behind the No. 50201 working face. The lagged influence of the two sides of the auxiliary transportation main roadway is
$115 \mathrm{~m}$ behind the No. 50114 working face. The lagged influence range of the belt conveying main roadway is 235 $\mathrm{m}$ behind the No. 50201 working face. The lagged influence range of the auxiliary transportation main roadway floor is $60 \mathrm{~m}$ behind the No. 50114 working face. The lagged influence range of the floor of the belt conveying main roadway is $90 \mathrm{~m}$ behind the No. 50201 working face.

After the intersection of the working faces, the advance influence range of the auxiliary transportation main roadway 
is $150 \mathrm{~m}$ in front of the No. 50114 working face, and the lagged influence range is $170 \mathrm{~m}$ behind the No. 50114 working face. The lagged influence range of the roof of the belt conveying main roadway is $50 \mathrm{~m}$ behind the No. 50201 working face. The lagged influence range of the two sides of the auxiliary transportation roadway is $90 \mathrm{~m}$ behind the No. 50114 working face. The lagged influence range of the two sides of the belt conveying main roadway is $80 \mathrm{~m}$ behind the No. 50201 working face. The lagged influence range of the floor of the auxiliary transportation main roadway is 20-50 $\mathrm{m}$ behind the No. 50114 working face, and the lagged influence range of the floor of the belt conveying main roadway is $30-80 \mathrm{~m}$ behind the No. 50201 working face.

Figure 10 demonstrates that when the surrounding rock of the main roadway is affected by single-sided mining, as shown as Fig. 10 (a), plastic zones appear at basic angles on both sides of the roof and floor. As the working faces on both sides of the main roadway continue to advance, the plastic zones at the two corners extend gradually to the middle of the roof and floor, as shown in Fig. 10 (b), until the shallow part of the roof and floor is destroyed, as shown in Fig. 10 (c). The results in Table 5 show that the plastic zone of the roof extends axially to a range of approximately $\pm 150 \mathrm{~m}$ with the staggered expansion of the two working faces. The range of the floor is $\pm 50 \mathrm{~m}$. The plastic zones of the two sides are small. Therefore, the 45-degree angles on both sides of the main roadway roof are the "key part" of the broken surrounding rock in the plastic zone of the main roadway.
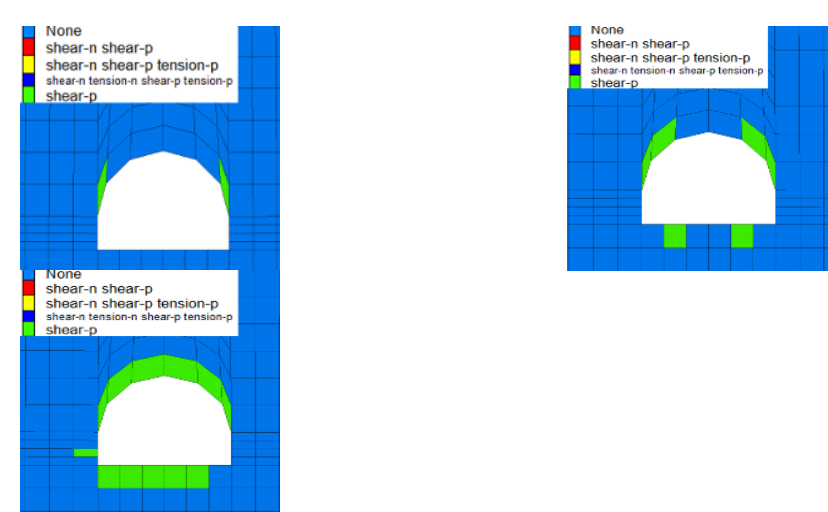

(a) single-sided mining (b) plastic zone expansion (c) double-sided mining Fig. 10. Failure law of surrounding rock in main roadway

\subsection{Analysis of key control technology for surrounding rock of double-sided mining roadway}

The key part of restraining the gradual and malignant expansion of the main roadway roof deep part and the axial direction of the roadway under the influence of double-sided mining is to strengthen the support of the key part before the main roadway is affected by double-sided mining. This action can ensure the stability of the surrounding rock in the region severely affected by mining stress. Moreover, it can restrain the malignant expansion of the plastic zone and eliminate roof hazards.

This study proposes a key control technology system with a space trinity of "Key strata + Key part + Key area." This system forms a united support system in three key locations in space. In addition, this system can improve the bearing capacity of the "Key strata" of the unstable rock stratum in the weak composite roof of the main roadway and restrain the malignant expansion of the "Key part" of the main roadway surrounding the rock plastic zone. The system ensures the stability of the "Key area" surrounding rock in a location under the severe influence of mining stress. Thus, the system can prevent the slag falling off the large concrete from hurting people, ensure smooth pedestrians and vehicles in the main roadway, reduce the maintenance cost of the main roadway, and ensure safe and effective mining.

Under the influence of single-sided mining, a large area of slag from the concrete of the roadway roof can drop vertically owing to roadway roof pressure. After being affected by double-sided mining, horizontal stress on the roof increases sharply. Thus, before the main roadway is affected by double-sided mining, reasonable reinforcement support should be implemented in advance. Given that the length of the bolt is shorter than the 0-3 m range of the "Key strata" of the unstable stratum in the weak composite roof of the main roadway, a $17.8 \mathrm{~mm} \times 7900 \mathrm{~mm}$ anchor cable made of existing support material in the Hecaogou coal mine is used to control the "Key strata." In this way, the bearing capacity of the "Key strata" of the unstable stratum in the 0 $3 \mathrm{~m}$ range of the main roadway weak composite roof is improved. Given that the 45-degree angles on both sides of the roadway roof are the "Key part" of the broken surrounding rock in the plastic zone of the main roadway, each additional anchor cable should be installed on the two vertex angles of the main roadway to restrain the malignant expansion of the "Key part" of the broken surrounding rock in the plastic zone of the two vertex angles of the roadway. In the "Key area" $150 \mathrm{~m}$ before and $150 \mathrm{~m}$ after the intersection of the two working faces, which is a region severely affected by mining stress, the $300 \mathrm{~m}$ concentrated roof area at the intersection of the two working faces is selected for hanging the net + anchor cable + ladder beam support (Fig. 11).

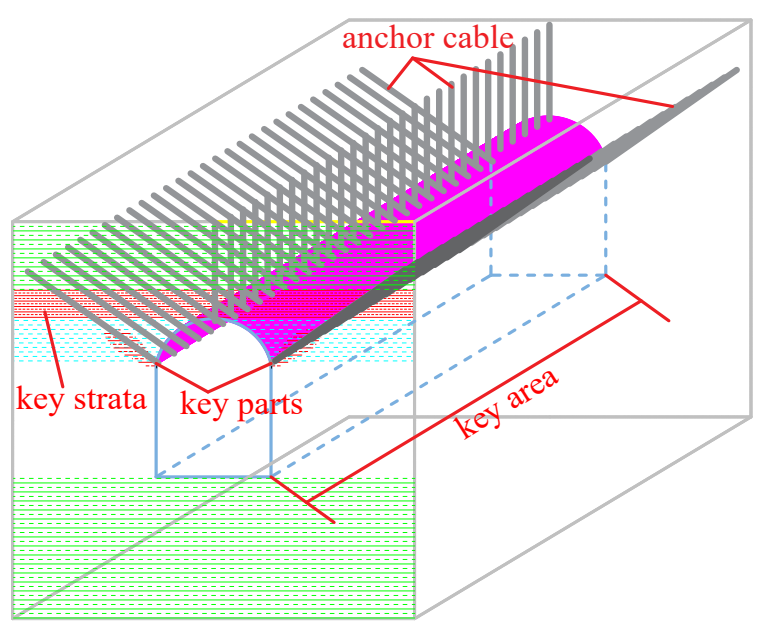

Fig. 11. Control scheme of the west area main roadway

\subsection{Surrounding rock control effect of test roadway analysis}

With the advancement of working faces No. 50114 and No. 50201 in the test roadway in the opposite direction, the deformation of the roof, floor, and two sides of the roadway increases slightly (Fig. 12). The displacement of the roof and floor is less than $20 \mathrm{~mm}$ and that of the two sides is less than $30 \mathrm{~mm}$. The key reinforcing support can maintain the stability of the surrounding rock effectively. 


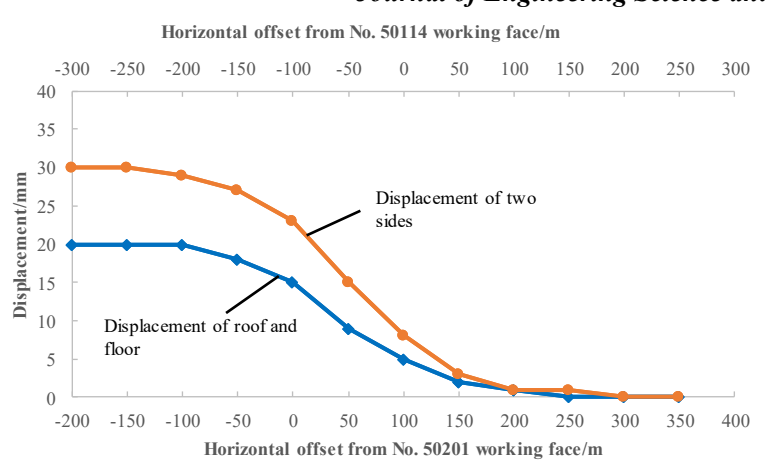

(a) Measuring point at $1100 \mathrm{~m}$ of the west area main return roadway

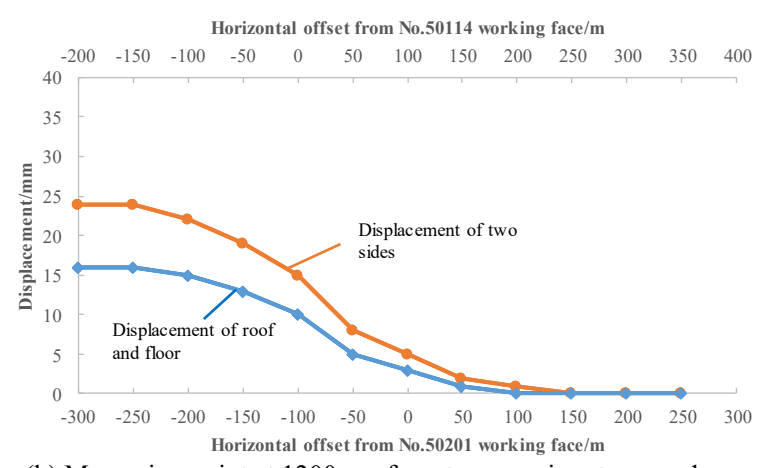

(b) Measuring point at $1200 \mathrm{~m}$ of west area main return roadway

Fig. 12. Surface displacement observation curve

The key reinforcing support controls the continued failure of the roof effectively, and the concrete gunite layer will not fall off until the two working faces intersect and stagger and mining has been completed (Fig. 13). The main roadway remains stable, and the control effect is satisfactory, which can effectively prevent a large area of the concrete slag from falling off and hurting people, eliminate hidden roof hazards, reduce the maintenance cost of the main roadway, and ensure safe and efficient mining.
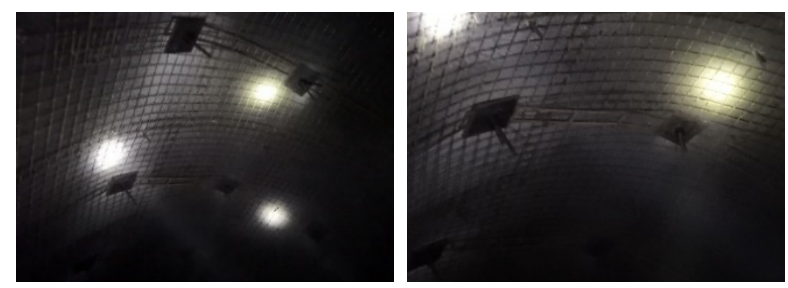

Fig. 13. Control effect of surrounding rock in main roadway after single-sided mining

\section{Conclusions}

This study explored the structural characteristics of main roadway surrounding rock, established the FLAC3D finite difference numerical modeling of the actual size of a mine, and analyzed the distribution rules of the main roadway surrounding rock stress and plastic zone affected by doublesided mining to prevent the instability of a main roadway surrounding rock affected by double-sided superimposed mining. On this basis, a main roadway surrounding rock control technology for double-sided mining was presented, and engineering verification was implemented. The following conclusions can be drawn.

(1) The characteristics of the surrounding rock structure combination of the west area main roadway were mastered, and the thickness and distribution of the bauxite mudstone interlayer in the oil shale in the range of $0-3 \mathrm{~m}$ on the roof of the west area main roadway were verified. Four types of bauxite mudstone enrichment areas were identified, that is, a soil bauxite mudstone rock line $(0-1 \mathrm{~cm})$ enrichment area, an extremely thin stratum $(1-2 \mathrm{~cm})$ enrichment area, a thin stratum $(5-10 \mathrm{~cm})$ enrichment area, and an interlayer of bauxite mudstone and oil shale "marbled meat."

(2) The superposition effect of the stress field of the double-sided mining main roadway surrounding rock and failure rule were obtained. The stability of the surrounding rock was dominated by horizontal stress. When the main roadway surrounding rock was under single-sided mining, plastic zones appeared at two corners on both sides of the roof. As the working faces on both sides of the main roadway advanced, the plastic zones at the two corners gradually expanded to the middle of the roof and floor until the entire shallow parts of the roof and floor were completely destroyed.

(3) A trinity control technology scheme of "Key strata + Key part + Key area" was proposed, and the engineering was verified. The control effect of this scheme was satisfactory, and a large area of slag falling off the concrete of the main roadway, which may cause injuries, was prevented effectively. The hidden hazards of roadway roof collapse were eliminated, the maintenance cost of the roadway was reduced, and safe and efficient mining was ensured.

Overall, the space trinity key control technology scheme of the double-sided mining main roadway proposed in this study contained clear support ideas. Existing anchor cables were used to reinforce the key part, and the construction was simple. Thus, satisfactory experimental results were obtained. However, in the analysis of the surrounding rock plastic zone, the size of the modeling FLAC3D was very large; thus, it was limited by computational power. Precise modeling could not be realized around the main roadway. Moreover, the interlayer of the roof mudstone was not analyzed in detail. In addition, the calculated results may differ from the actual result. Therefore, roof mudstone layer factors should be studied in future research.

\section{Acknowledgements}

This work was supported by the National Natural Science Foundation of China (No. 51804118) and the Fundamental Scientific Research Business of Central Universities from the North China Institute of Science and Technology (No. 3142018021, 3142017085).

This is an Open Access article distributed under the terms of the Creative Commons Attribution License

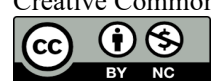

\section{References}

1. Zhang, D. L., Wang, Y. H., Qu, T. Z., "Influence analysis of interband on stability of stratified rockmass". Chinese Journal of Rock Mechanics and Engineering, 19(2), 2000, pp.140-144. 
Lv Kun, Chen Yidong, Feng Jicheng, Wang Jinguo, Guo Qing, Wei Penghui and Shen Jinchao/

\section{Journal of Engineering Science and Technology Review 13 (2) (2020) 174 - 184}

2. Xie, H. P., Gao, M. Z., Zhang, R., Peng, G. Y., Wang, W. Y., Li A. Q., "Study on the mechanical properties and mechanical response of coal mining at $1000 \mathrm{~m}$ or deeper". Rock Mechanics and Rock Engineering, 52, 2019, pp.1475-1490.

3. Spagnoli, G., Oreste, P., Bianco, L. L., "New equations for estimating radial loads on deep shaft linings in weak rocks". International Journal of Geomechanics, 16(6), 2016, pp. 06016006.

4. Oreste, P., Hedayat, A., Spagnoli, G., "Effect of gravity of the plastic zones on the behavior of supports in very deep tunnels excavated in rock masses". International Journal of Geomechanics, 19(9), 2019, pp.04019107.

5. Walton, G., Kim, E., Sinha, S., Sturgis, G., Berberick, D. M., "Investigation of shaft stability and anisotropic deformation in a deep shaft in Idaho, United States". International Journal of Rock Mechanics and Mining Sciences, 105, 2018, pp.160-171.

6. Zhang, W., He, Z. M., Zhang, D. S., Qi, D. K., Zhang, W. S., "Surrounding rock deformation control of asymmetrical roadway in deep three-soft coal seam: a case study". Journal of Geophysics and Engineering, 15(5), 2018, pp.1917-1928.

7. Masoudi, R., Sharifzadeh, M., "Reinforcement selection for deep and high-stress tunnels at preliminary design stages using ground demand and support capacity approach". International Journal of Mining Science and Technology, 28(4), 2018, pp.573-582.

8. Liu, Y. R., Tang, H. M., "Rockmass mechanics". China University of Geosciences Press, Wuhan, China: 1999, pp.154-157.

9. Zareifard, M. R., Fahimifar, A., "Elastic-brittle-plastic analysis of circular deep underwater cavities in a Mohr-coulomb rock mass considering seepage forces". International Journal of Geomechanics, 15(5), 2015, pp. 04014077.

10. Sharan, S.K., "Elastic-brittle-plastic analysis of circular openings in Hoek-brown media". International Journal of Rock Mechanics \& Mining Sciences, 40(6), 2003, pp.817-824.

11. Park, K. H., Kim, Y. J., “Analytical solution for a circular opening in an elastic-brittle-plastic rock". International Journal of Rock Mechanics \& Mining Sciences, 43(4), 2006, pp.616-622.
12. Zheng, W. X., Bu, Q. W., Hu, Y. Q., "Plastic failure analysis of roadway floor surrounding rocks based on unified strength theory". Advances in Civil Engineering, 2018, pp.7475698.

13. Coggan, J., Gao, F. Q., Stead, D., Elmo, D., "Numerical modelling of the effects of weak immediate roof lithology on coal mine roadway stability". International Journal of Coal Geology, 90, 2012, pp. 100-109.

14. Basarir, H., Sun, Y. T., Li, G. C., "Gateway stability analysis by global-local modeling approach". International Journal of Rock Mechanics \& Mining Sciences, 113, 2019, pp.31-40.

15. Zhao, Z. Q., Ma, N. J., Guo, X. F., Zhao, X. D., Fan, L., "Falling principle and support design of butterfly-failure roof in large deformation mining roadways". Journal of China Coal Society, 41(12), 2016, pp.2932-2939.

16. Tai, Y., Xia, H. C., Kuang, T. J., "Failure characteristics and control technology for large-section chamber in compound coal seams-A case study in Tashan Coal Mine". Energy Science \& Engineering, 2019, pp.1-17.

17. Jia, H. S., Pan, K., Liu, S. W., Peng, B., Fan, K., "Evaluation of the mechanical instability of mining roadway overburden: research and applications". Energies, 12(22), 2019, pp.4265.

18. Pan, R. K., Ma, Z. H., Yu, M. G., Wu, S. D., "Research on the deformation characteristics and support technology of a bottom gas extraction roadway under repeated interference". Advances in Civil Engineering, 2019, pp.1413568.

19. Xu, Y. L., Pan, K. R., Zhang, H., "Investigation of key techniques on floor roadway support under the impacts of superimposed mining: theoretical analysis and field study". Environmental Earth Sciences, 78, 2019, pp.436.

20. Zhang, Y. D., Yang, Y. J., Zhuge, C. H., "Deformation caused by dynamic load and support requirements in a deep gob-side entry rock mass". Advances in Materials Science and Engineering, 2019, pp.4530954.

21. Yuan, H. H., Shan, R. L., Su, X. G., "Deformation characteristics and stability control of a gateroad in fully mechanized mining with large mining height”. Arabian Journal of Geosciences, 11, 2018, pp.767. 